\title{
HBV X gene point mutations are associated with the risk of hepatocellular carcinoma: A systematic review and meta-analysis
}

\author{
YULAN WANG, LI ZENG and WEIQING CHEN
}

\author{
Department of Gastroenterology and Respiratory Medicine, Chongqing Cancer Hospital \\ and Institute and Cancer Center, Chongqing 400030, P.R. China
}

Received May 7, 2015; Accepted November 16, 2015

DOI: $10.3892 / \operatorname{mco} .2016 .847$

\begin{abstract}
Previous evidence suggests that the accumulation of the hepatitis $\mathrm{B}$ virus (HBV) $\mathrm{X}$ gene region point mutations may be associated with the development of hepatocellular carcinoma (HCC). However, the pathogenesis of HCC remains to be elucidated. The aim of the present meta-analysis was to investigate the association between the HBV $\mathrm{X}$ gene point mutations and the risk of HCC. Studies were collected regarding the association between HBV X gene point mutations and the risk of HCC, which were identified in PubMed, EMBASE and China National Knowledge Infrastructure databases. The results were evaluated by use of odds ratios (ORs) and its $95 \%$ confidence intervals (CIs), which were pooled by random or fixed effects. A total of 11 studies involving 2,502 patients were included in this meta-analysis. Statistical summary ORs of HBV X gene point mutations were obtained for T1653 (OR, 3.11; 95\% CI, 2.22-4.36), V1753 (OR, 2.55; 95\% CI, 1.66-3.92), and T1762/A1764 (OR, 4.49; 95\% CI, 2.86-7.07). HBV X gene point mutations T1653, V1753 and T1762/A1764 could increase the risk of HCC significantly, particularly the T1762/A1764 double mutations. These mutations may be predictive for hepatocarcinogenesis. However, these results of the meta-analysis should be treated carefully due to a low level of evidence.
\end{abstract}

\section{Introduction}

Hepatocellular carcinoma (HCC) is the fifth most common cancer worldwide, which is a serious risk to human health $(1,2)$. However, the pathogenesis of HCC has not been fully elucidated. Hepatitis B virus (HBV) chronic infection is considered one of the major risk factors for the development of HCC (3-5).

Correspondence to: Professor Weiqing Chen, Department of Gastroenterology and Respiratory Medicine, Chongqing Cancer Hospital and Institute and Cancer Center, 181 Hanyu Road, Chongqing 400030, P.R. China

E-mail: chenwq20140809@163.com

Key words: hepatitis B virus X gene, hepatocellular carcinoma, meta-analysis, point mutation
The HBV genome is an incomplete double-stranded circular structure, containing 4 open reading frames (ORF): $\mathrm{S}, \mathrm{C}, \mathrm{P}$ and $\mathrm{X}(6,7)$. ORF region mutations could alter viral replication and virulence force, which lead to a persistent virus infection and severe liver cell damage, and eventually result in the development of $\mathrm{HCC}(8,9)$. The precore region encodes the hepatitis $\mathrm{B}$ e-antigen $(\mathrm{HBeAg})$, which has been associated with an increased risk of HCC statistically. Certain studies have shown that HBV $\mathrm{X}$ gene point mutations can affect the expression of HBeAg and increase the viral replication capacity $(8,10,11)$. In recent years, the association between HBV mutations and the incidence of HCC has focused on the $\mathrm{X}$ gene region, the former $\mathrm{C}$ gene region and pre-S gene region, and the $\mathrm{X}$ gene region is the most important.

Previously, certain studies have identified that the $\mathrm{X}$ gene region T1653, V1753, T1762/A1764 and other point mutations may be associated with persistent $\mathrm{HBV}$ infection and the development of HCC (6,10-13). However, there remains certain controversy and further research is required. Therefore, the present meta-analysis was performed to investigate the association between HBV $\mathrm{X}$ gene point mutations and the development of HCC systematically and comprehensively.

\section{Materials and methods}

Search strategy. Two authors (Wang and Zeng) searched PubMed, EMBASE, the Cochrane Library and Chinese National Knowledge Infrastructure for the relevant studies. The key words included: 'Hepatitis B virus X gene', 'mutation', 'liver cancer or hepatocellular carcinoma'. The searches were limited to human subjects. Language restriction was not imposed on the search process. In addition, the reference lists of the included studies were checked manually for other potentially eligible studies. This process was repeated until no additional associated studies could be identified.

Inclusion criteria. The inclusion criteria included: i) Study design for the prevalence of case-control; ii) the diagnoses of chronic hepatitis B, liver cirrhosis and HCC were according to the guidelines of the American Association for the Study of Liver Diseases (14); iii) all HBsAg-positive patients were infected with $\mathrm{HBV}>2$ years and the HBV DNA level was in accordance with the test standard; and iv) the reported outcomes of patients was HCC. 
Exclusion criteria. The exclusion criteria included: i) Patients with HCV, HDV or human immunodeficiency virus infection; ii) patients with alcoholic liver disease, autoimmune disease or drug-induced liver disease; iii) patients with antiviral treatment; iv) if similar research was reported by the same author, only the recent study or high-quality study was included in this analysis.

Data extraction and quality evaluation. Data extraction and quality evaluation of studies were conducted by 2 independent authors (Wang and Chen). The extracted data included first author, publication year, country, study design, quality score, cases of patients (number of events and total patients), age, gender, alanine aminotransferase and HBV DNA level, genotypes, mutation sites and detection method. The evaluation standard was in accordance with the methods of the study by Liu et al (15). Discussion or a third investigator aided in solving any disagreements.

Statistical analysis. The odds ratios (ORs) with 95\% confidence intervals (CIs) of binary end points were analyzed. Heterogeneity was checked using $\chi^{2}$ test, P-values and $\mathrm{I}^{2}$. The random effects model was used when $\mathrm{P}<0.1$; otherwise the fixed effects model was used when $P \geq 0.1$. Sensitivity analysis was conducted by eliminating one study in turn in the analysis. Potential publication bias was evaluated by visual inspection of the Begg funnel plots in which the log ORs were plotted against their standard errors. All the data were calculated by RevMan 5.0 software (Copenhagen: The Nordic Cochrane Centre, The Cochrane Collaboration).

\section{Results}

Study characteristics. According to the inclusion and exclusion criteria of the literature, 11 studies involving 2,502 patients were included in this meta-analysis, of whom 2,801 had HCC. These studies included 1 study in Chinese and 10 in English $(6,11,13,16-23)$. A detailed flow chart explaining the inclusion of studies is shown in Fig. 1. The extracted information from the studies included: i) The publication year of the studies was between 1999 and 2013; ii) the study design were case-control studies; iii) the countries of the studies included mainland China, Hong Kong, South Korea and Thailand. A summary of the 11 included studies is shown in Table I. The details of the quality criteria based on factors are listed in Table II.

Meta-analysis. All 11 studies involving 2,502 patients reported that the relevant outcome of the T1653, V1753 and T1762/A1764 point mutations were associated with the risk of HCC. The results of the meta-analysis showed that T1653 (OR, 3.11; 95\% CI, 2.22-4.36) (Fig. 2), V1753 (OR, 2.55; 95\% CI, 1.66-3.92) (Fig. 3) and T1762/A1764 (OR, 4.49; 95\% CI, 2.86-7.07) (Fig. 4) increase the risk of HCC.

Subgroup analysis. The summary ORs for HBV X gene mutations were explored by $\mathrm{HBeAg}$ status, country and quality score. The summary OR of the T1762/A1764 double mutations in $\mathrm{HBeAg}(+)$ group were lower compared to the HBeAg (-) group, whereas the T1653 and V1753 mutations

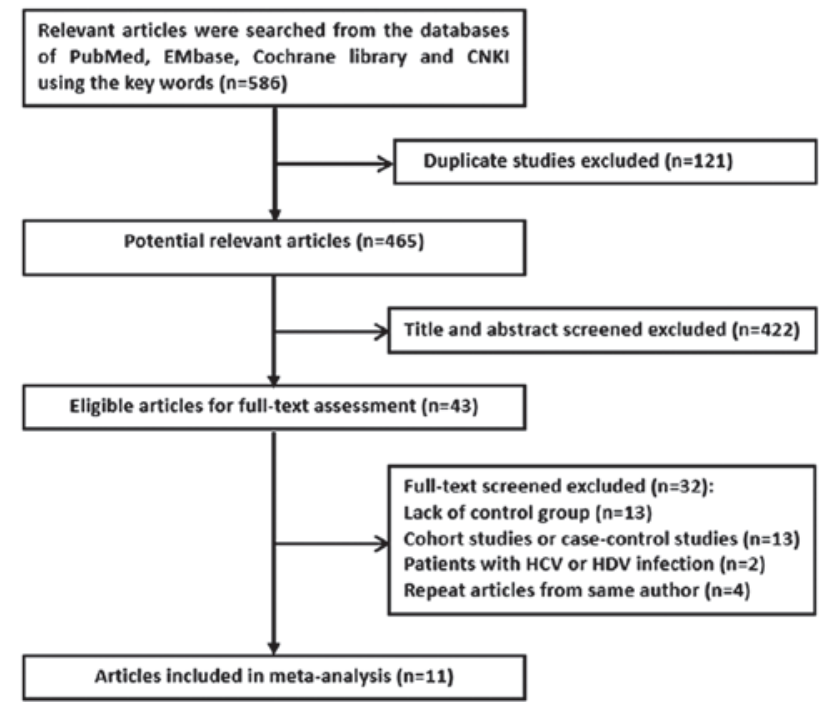

Figure 1. Flow diagram of the relevant studies included in the meta-analysis. $\mathrm{HCV}$, hepatitis $\mathrm{C}$ virus.

were higher. There is no significant difference in the results between subgroup and overall analyses except for the V1753 point mutation for the risk of HCC in patients from Korea. The result suggested that there was no statistically significant associations between the V1753 mutation and the risk of HCC in Korean patients (OR, 1.25; 95\% CI, 0.69-2.26) (Table III). The summary ORs for T1653, V1753 and T1762/A1764 increased with decreasing study quality score (Table III).

Sensitivity analysis and publication bias. The effect of a single study on the overall pooled analyses was investigated by sensitivity analysis to evaluate the heterogeneity of each study. There were no significant influences observed when one study was removed each turn. The funnel plot showed an asymmetrical distribution of these studies, indicating that publication bias existed in these results regarding an association between T1653 (Fig. 5A), V1753 (Fig. 5B) and T1762/A1764 (Fig. 5C) point mutations and the risk of $\mathrm{HCC}$.

\section{Discussion}

Meta-analysis is regarded as a qualitative and quantitative tool to solve those problems that remain controversial in clinical settings. The results of the meta-analysis were the highest level of evidence. The debate on the association between HBV gene mutations and development of HCC is ongoing. Recently, a series of studies on this subject have been published. Therefore, the present meta-analysis was performed and the results showed that T1653, V1753 and T1762/A1764 mutations could significantly increase the risk of HCC, particularly the T1762/A1764 double mutations.

HBV chronic infection is the most important risk factor for the development of HCC (24). Lin et al (25) considered that the transactivation function of the carboxyl terminus of the HBV X protein would regulate HBV DNA replication and transcription of liver cell proliferation and differentiation. As well as T1653, V1753 and T1762/A1764 mutations are all located in the carboxyl terminus region of the HBV X protein. 


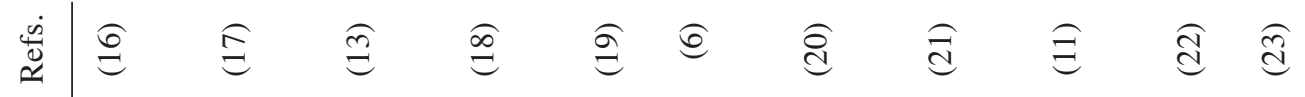

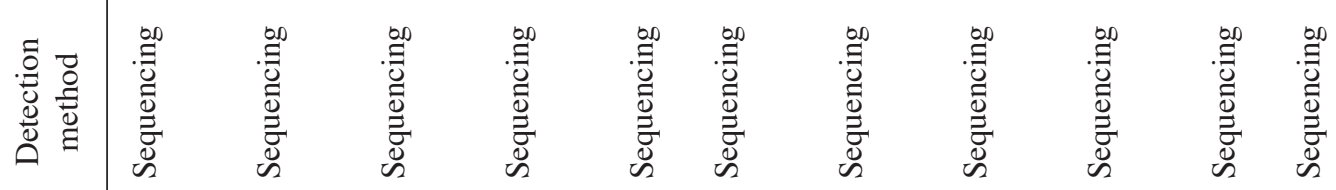
苦 $\stackrel{\text { n }}{\frac{n}{5}}$

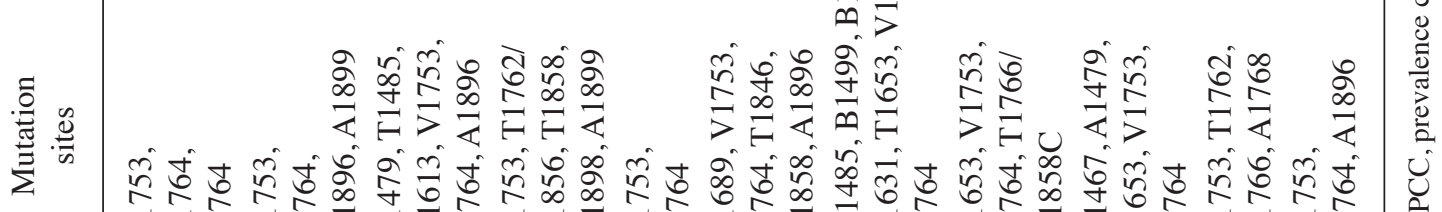

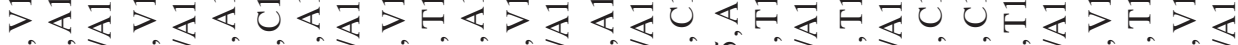

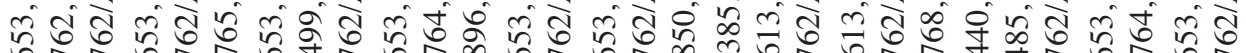

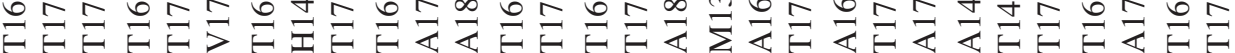

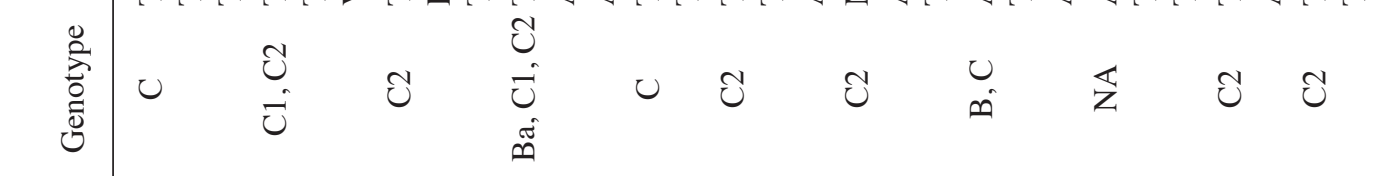

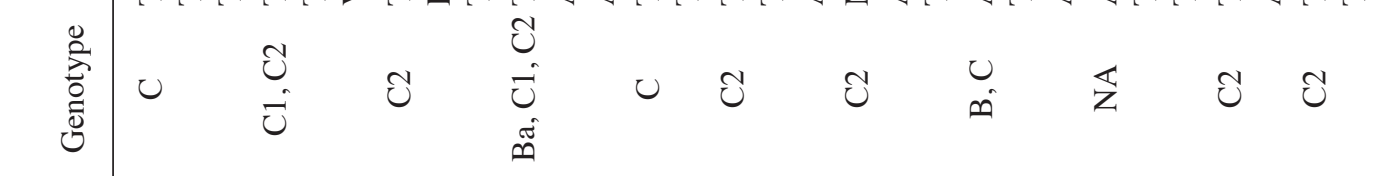

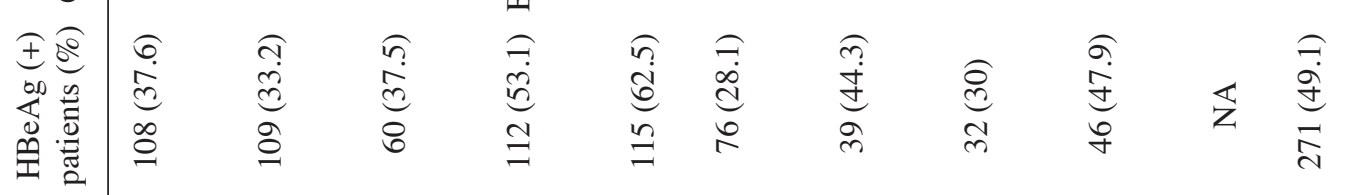

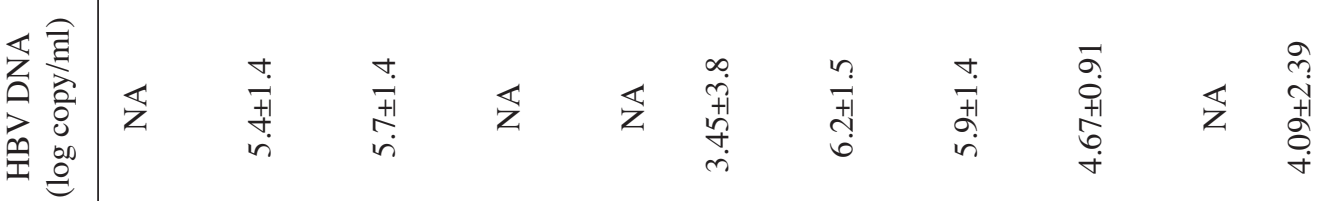

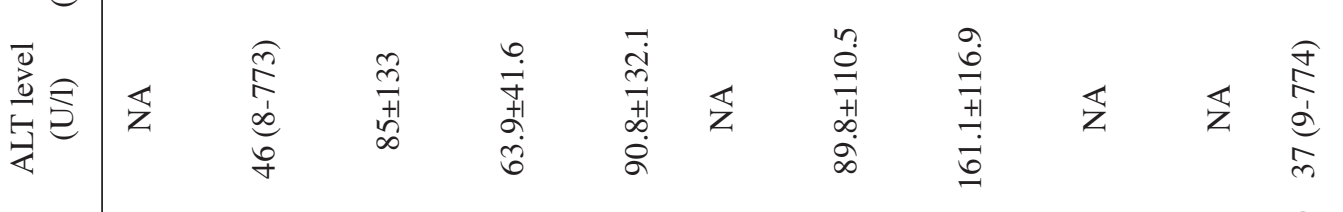

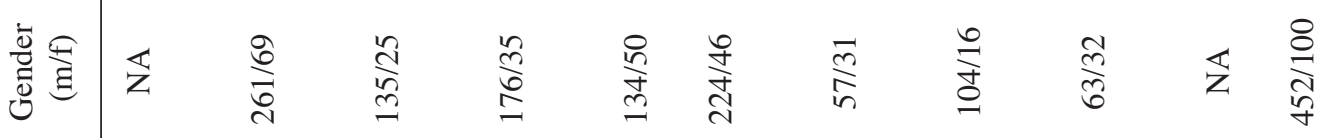

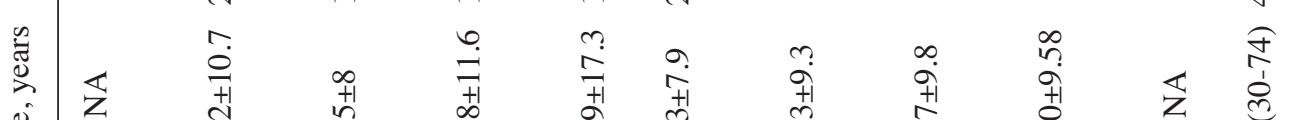

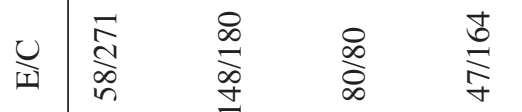

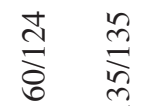

$\frac{2}{2} \frac{8}{2}$

$\frac{n}{2}$

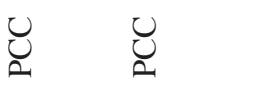

$\breve{\sharp}$

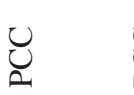

唄

言 㒸 
Table II. Details of the quality criteria for studies included in the meta-analysis.

Score

Quality parameter

0

2

Study design

Sample size of cases

Source of samples

Mutation detection method

Matching of cases and controls
Cohort or nested case-control

$<50$

None

None

None

None
Incidence case-control

50-100

1 hospital

Others

Age or gender

HBeAg or genotype
Prevalence case-control $\geq 100$

$\geq 2$ hospitals

DNA sequencing

Age and gender HBeAg and genotype

HBeAg, hepatitis B e-antigen.

\begin{tabular}{|c|c|c|c|c|c|c|c|c|c|}
\hline \multirow[b]{2}{*}{ Study or Subgroup } & \multicolumn{2}{|c|}{ HCC group } & \multicolumn{2}{|c|}{ non-HCC group } & \multicolumn{2}{|r|}{ Odds Ratio } & \multirow{2}{*}{\multicolumn{3}{|c|}{$\begin{array}{c}\text { Odds Ratio } \\
\text { M-H. Random. } 95 \% \mathrm{Cl}\end{array}$}} \\
\hline & Events & Total & Events & Total & Weight & M-H, Random, $95 \% \mathrm{Cl}$ Year & & & \\
\hline Tanaka.Y [17] & 58 & 148 & 44 & 180 & $13.8 \%$ & $1.99[1.24,3.20] 2006$ & & & \\
\hline Wang. $Z[18]$ & 9 & 47 & 3 & 164 & $4.7 \%$ & $12.71[3.28,49.21] 2007$ & & & \\
\hline $\mathrm{Kim} . \mathrm{H}[19]$ & 24 & 60 & 23 & 124 & $10.6 \%$ & $2.93[1.47,5.82] 2008$ & & & \\
\hline Choi.C [20] & 21 & 42 & 15 & 46 & $8.4 \%$ & $2.07[0.87,4.90] 2009$ & & & \\
\hline Li.W [22] & 18 & 102 & 9 & 105 & $8.6 \%$ & $2.29[0.97,5.36] 2013$ & & & \\
\hline Lyu.H [23] & 70 & 318 & 26 & 234 & $13.6 \%$ & $2.26[1.39,3.67] 2013$ & & $\longrightarrow$ & \\
\hline Shi.W [11] & 11 & 41 & 7 & 54 & $6.6 \%$ & $2.46[0.86,7.05] 2013$ & & & \\
\hline Total $(95 \% \mathrm{Cl})$ & & 1086 & & 1416 & $100.0 \%$ & $3.11[2.22,4.36]$ & & & \\
\hline Total events & 310 & & 182 & & & & & & \\
\hline
\end{tabular}

Figure 2. Forest plot for the odds ratios of T1653 for the risk of HCC. HCC, hepatocellular carcinoma; CI, confidence interval; M-H, Mantel-Haensze.

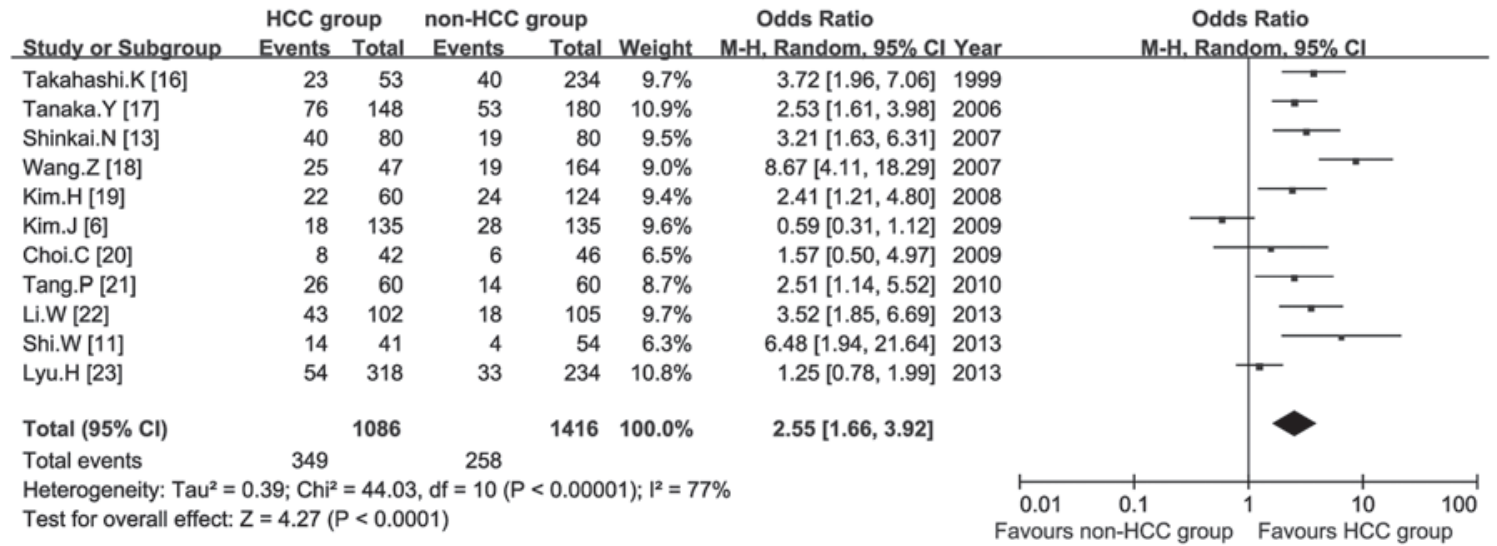

Figure 3. Forest plot for the odds ratios of V1753 for the risk of HCC. HCC, hepatocellular carcinoma; CI, confidence interval; M-H, Mantel-Haensze.

Kim et al (19) suggested that T1653, V1753 and T1762/A1764 mutations would change the sequence of HBV X protein amino acids, further leading to the activation of proto-oncogenes and inactivation of the tumor suppressor gene, eventually causing the occurrence of HBV-related HCC. However, the mechanism of how the point mutations of HBV X gene region affect the biological function of HBV X protein remains to be elucidated in further studies.
Liu et al (15) considered that the $\mathrm{HBeAg}$ status would affect the point mutation type of the HBV X gene and development of HCC. Previous studies suggested that the expression of $\mathrm{HBeAg}$ is often significantly correlated with immune evasion and acted as an indicator of active viral replication $(26,27)$. In the subgroup analysis, data on the HBeAg status was extracted, which was a potential confounder, and identified that T1762/A1764 double mutations could decrease HBeAg 
Table III. Subgroup analyses based on the main characteristics of the included studies.

\begin{tabular}{|c|c|c|c|c|c|c|c|c|c|}
\hline \multirow[b]{2}{*}{ Characteristics } & \multicolumn{3}{|c|}{$\mathrm{T} 1653$} & \multicolumn{3}{|c|}{ V1753 } & \multicolumn{3}{|c|}{ T1762/A1764 } \\
\hline & $\mathrm{T} / \mathrm{P}$ & OR $(95 \% \mathrm{CI})$ & Model & $\mathrm{T} / \mathrm{P}$ & OR $(95 \% \mathrm{CI})$ & Model & $\mathrm{T} / \mathrm{P}$ & OR $(95 \% \mathrm{CI})$ & Model \\
\hline \multicolumn{10}{|l|}{$\mathrm{HBeAg}$} \\
\hline+ & $5 / 392$ & $3.25(1.87-5.66)$ & Fixed & $5 / 392$ & $2.50(1.52-4.12)$ & Fixed & $6 / 536$ & $3.15(2.03-4.89)$ & Fixed \\
\hline- & $5 / 741$ & $2.56(1.78-3.68)$ & Fixed & $5 / 741$ & $1.84(1.32-2.58)$ & Fixed & $6 / 911$ & $5.50(2.64-11.46)$ & Fixed \\
\hline \multicolumn{10}{|l|}{ Country } \\
\hline China & $3 / 513$ & $3.23(1.80-5.79)$ & Fixed & $3 / 513$ & $5.17(3.28-8.13)$ & Fixed & $3 / 513$ & $5.99(2.17-16.53)$ & Random \\
\hline Japan & $3 / 775$ & $3.78(1.52-9.41)$ & Random & $3 / 775$ & $2.93(2.11-4.06)$ & Fixed & $3 / 775$ & $4.27(2.68-6.80)$ & Fixed \\
\hline Korea & $4 / 1,094$ & $2.50(1.77-3.54)$ & Fixed & $4 / 1,094$ & $1.25(0.69-2.26)$ & Random & $4 / 1,094$ & $3.58(1.46-8.79)$ & Random \\
\hline Thailand & $1 / 120$ & 2.75 (1.04-7.29) & NA & $1 / 120$ & $2.51(1.14-5.52)$ & NA & $1 / 120$ & $6.19(2.42-15.83)$ & NA \\
\hline \multicolumn{10}{|l|}{ Quality score } \\
\hline$>6$ & $8 / 2,108$ & $3.05(2.10-4.42)$ & Random & $8 / 2,108$ & $2.14(1.39-3.28)$ & Random & $8 / 2,108$ & $3.66(2.30-5.81)$ & Random \\
\hline$\leq 6$ & $3 / 394$ & $3.11(1.74-5.59)$ & Fixed & $3 / 394$ & $5.18(2.98-9.02)$ & Fixed & $3 / 394$ & $9.60(5.14-17.93)$ & Fixed \\
\hline
\end{tabular}

HBeAg, hepatitis B e-antigen; NA, not available; OR, odds ratio; T/P, no. of trials/no. of patients.

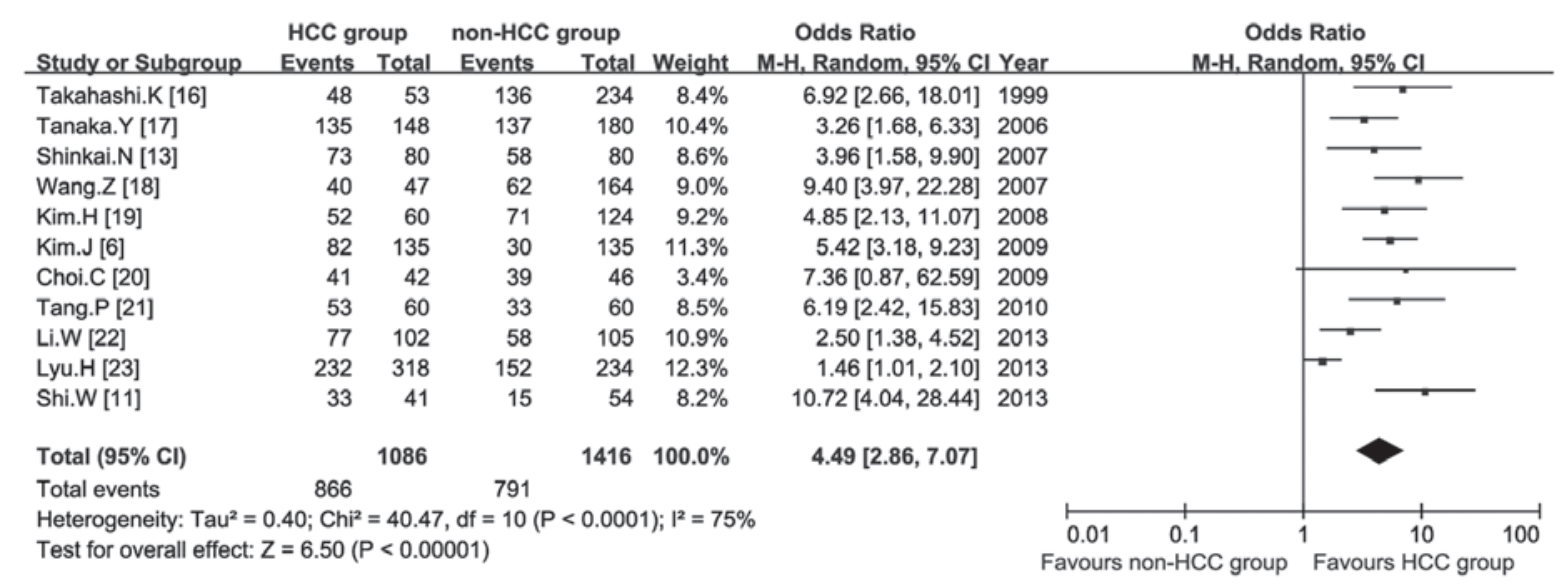

Figure 4. Forest plot for the odds ratios of T1762/A1764 for the risk of HCC. HCC, hepatocellular carcinoma; CI, confidence interval; M-H, Mantel-Haensze.

A

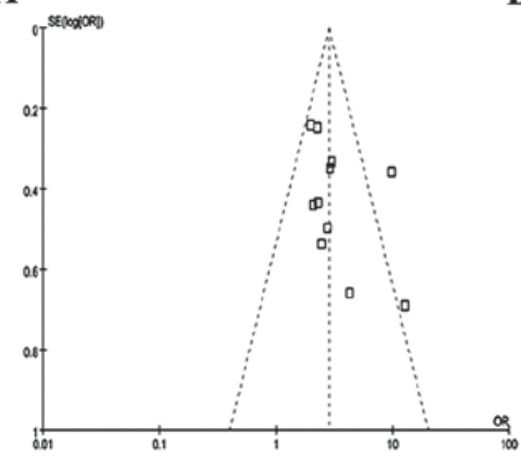

B

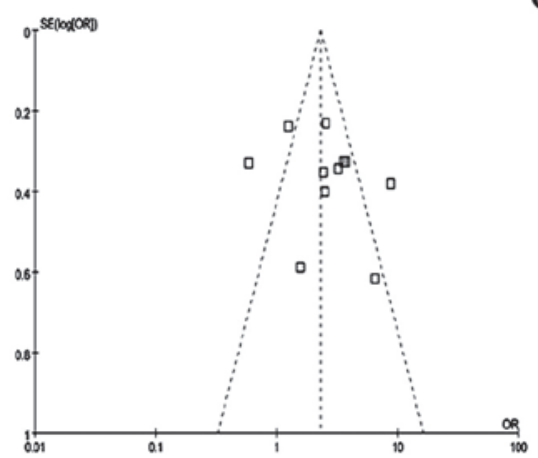

C

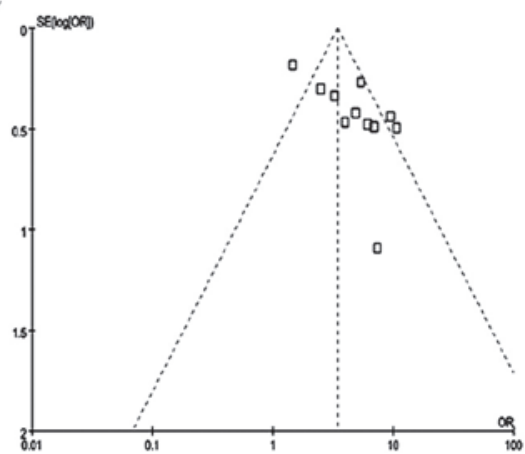

Figure 5. Funnel plot regarding the publication bias of (A) T1653, (B) V1753 and (C) T1762/A1764 for the risk of hepatocellular carcinoma. OR, odds ratio; SE, standard error.

expression. However, a large number of studies showed that T1762/A1764 double mutations could enhance the virus replication. The contradiction indicated that the decrease of
HBeAg expression did not equate to an improved development of HCC. Persistent chronic HBV infection may be due to HBV immune escape, which further aggravates the condition 
of patients and eventually results in $\mathrm{HCC}(28,29)$. Li et al (22) reported that T1762/A1764 double mutations could not predict the development of HCC. However, the present study identified that double mutations were more closely associated with the risk of HCC compared to T1653 or V1753 alone. Therefore, the combined mutations could lead to a higher incidence of liver cancer and improve the predictability of HCC.

The present findings showed that the summary ORs for T1653, V1753 and T1762/A1764 were higher in the low-quality compared to the high-quality studies. Potential confounders may have an important role in evaluating HBV mutations and the risk of HCC in low-quality studies. Yin et al (30) suggested that the average age of the patients with chronic hepatitis B was 10 years younger than that of the patients with HCC. Additionally, Yang et al (31) suggested that HBV mutations accumulated with increasing age. Therefore, the association between the HBV X gene point mutations and risk of $\mathrm{HCC}$ was more likely to be overestimated in the confounder-unmatched, low-quality studies.

The main characteristics embodied in the present study were: i) The association between HBV X gene mutations and development of HCC among various studies examined systematically and comprehensively, in order to have an improved understanding for the effect of HBV X protein on development of HCC; ii) a series of subgroup analyses were conducted to explore the effect of potential confounding factors on the development of HCC; and iii) the results suggested that these point mutations could be used as molecular markers of the risk of HCC. The limitations of the study were: i) The age, gender, genotype and other confounding factors could not be matched fully and the existence of various offsets requires further information and data to be confirmed; ii) only $3 \mathrm{HBV} \mathrm{X}$ gene mutations were analyzed in the meta-analysis, and there may be other gene mutations that affect the HBV X protein biological function as well as V1674, T1766 and A1768 mutations; and iii) the included studies were all observational case-control studies, as experimental studies could not be conducted in humans.

In the future, the mechanism of the HBV X gene region point mutations should focus on the biological function of the HBV X protein and the association with the development of HCC. In order to improve the prediction for HCC risk and reduce or even avoid the development of HCC, quicker and easier methods should be developed for the detection of HBV gene mutations.

\section{Acknowledgements}

The authors would like to thank Dr Longkun Li for providing methods of data analysis.

\section{References}

1. Cazzagon N, Trevisani F, Maddalo G, et al; Italian Liver Cancer (ITA.LI.CA) Group: Rise and fall of HCV-related hepatocellular carcinoma in Italy: A long-term survey from the ITA.LI.CA centres. Liver Int 33: 1420-1427, 2013.

2. Fares N and Peron JM: Epidemiology, natural history, and risk factors of hepatocellular carcinoma. Rev Prat 63: 216-217, 220-212, 2013 (In French).

3. Matsuda Y and Ichida T: Impact of hepatitis B virus X protein on the DNA damage response during hepatocarcinogenesis. Med Mol Morphol 42: 138-142, 2009.
4. Rawat S, Clippinger AJ and Bouchard MJ: Modulation of apoptotic signaling by the hepatitis B virus $\mathrm{X}$ protein. Viruses 4 : 2945-2972, 2012

5. Bouchard MJ and Navas-Martin S: Hepatitis B and C virus hepatocarcinogenesis: Lessons learned and future challenges. Cancer Lett 305: 123-143, 2011

6. Kim JK, Chang HY, Lee JM, Baatarkhuu O, Yoon YJ, Park JY, Kim Y, Han KH, Chon CY and Ahn SH: Specific mutations in the enhancer II/core promoter/precore regions of hepatitis B virus subgenotype $\mathrm{C} 2$ in Korean patients with hepatocellular carcinoma. J Med Virol 81: 1002-1008, 2009.

7. Liu L, Li Y, Zhang S, Yu D and Zhu M: Hepatitis B virus X protein mutant upregulates CENP-A expression in hepatoma cells. Oncol Rep 27: 168-173, 2012.

8. Tu H, Bonura C, Giannini C, Mouly H, Soussan P, Kew M, Paterlini-Bréchot $\mathrm{P}$, Bréchot $\mathrm{C}$ and Kremsdorf D: Biological impact of natural COOH-terminal deletions of hepatitis B virus X protein in hepatocellular carcinoma tissues. Cancer Res 61: 7803-7810, 2001.

9. Yeh CT, Shen CH, Tai DI, Chu CM and Liaw YF: Identification and characterization of a prevalent hepatitis $B$ virus $X$ protein mutant in Taiwanese patients with hepatocellular carcinoma. Oncogene 19: 5213-5220, 2000.

10. Kaneko M, Uchida T, Moriyama M, Arakawa Y, Shikata T, Gotoh K and Mima S: Probable implication of mutations of the $\mathrm{X}$ open reading frame in the onset of fulminant hepatitis B. J Med Virol 47: 204-208, 1995

11. Shi W, Wang Q, Zhao X and Zhao L: Study on the relationship between the mutations of hepatitis $\mathrm{B}$ virus $\mathrm{X}$ gene and precore gene, related factors and hepatocellular carcinoma. Chinas Med 8: 1673-4777, 2013 (In Chinese).

12. Uchida T, Saitoh T and Shinzawa H: Mutations of the $X$ region of hepatitis B virus and their clinical implications. Pathol Int 47: 183-193, 1997.

13. Shinkai N, Tanaka Y, Ito K, Mukaide M, Hasegawa I, Asahina Y, Izumi N, Yatsuhashi H, Orito E, Joh T, et al: Influence of hepatitis $\mathrm{B}$ virus $\mathrm{X}$ and core promoter mutations on hepatocellular carcinoma among patients infected with subgenotype C2. J Clin Microbiol 45: 3191-3197, 2007.

14. Cabibbo G, Antonucci $M$ and Genco $C$ : Update on new approaches in the management of hepatocellular carcinoma. Hepat Med 2: 163-173, 2010.

15. Liu S, Zhang H, Gu C, Yin J, He Y, Xie J and Cao G: Associations between hepatitis B virus mutations and the risk of hepatocellular carcinoma: A meta-analysis. J Natl Cancer Inst 101: 1066-1082, 2009.

16. Takahashi K, Ohta Y, Kanai K, Akahane Y, Iwasa Y, Hino K, Ohno $\mathrm{N}$, Yoshizawa $\mathrm{H}$ and Mishiro S: Clinical implications of mutations C-to-T1653 and T-to-C/A/G1753 of hepatitis B virus genotype C genome in chronic liver disease. Arch Virol 144: 1299-1308, 1999.

17. Tanaka Y, Mukaide M, Orito E, Yuen MF, Ito K, Kurbanov F, Sugauchi F, Asahina Y, Izumi N, Kato M, et al: Specific mutations in enhancer II/core promoter of hepatitis B virus subgenotypes $\mathrm{C} 1 / \mathrm{C} 2$ increase the risk of hepatocellular carcinoma. J Hepatol 45: 646-653, 2006.

18. Wang Z, Tanaka Y, Huang Y, Kurbanov F, Chen J, Zeng G, Zhou B, Mizokami M and Hou J: Clinical and virological characteristics of hepatitis $\mathrm{B}$ virus subgenotypes $\mathrm{Ba}, \mathrm{C} 1$ and $\mathrm{C} 2$ in China. J Clin Microbiol 45: 1491-1496, 2007.

19. Kim HJ, Park JH, Jee Y, Lee SA, Kim H, Song BC, Yang S, Lee M, Yoon JH, Kim YJ, et al: Hepatitis B virus X mutations occurring naturally associated with clinical severity of liver disease among Korean patients with chronic genotype $\mathrm{C}$ infection. J Med Virol 80: 1337-1343, 2008.

20. Choi CS, Cho EY, Park R, Kim SJ, Cho JH and Kim HC: X gene mutations in hepatitis B patients with cirrhosis, with and without hepatocellular carcinoma. J Med Virol 81: 1721-1725, 2009.

21. Tangkijvanich P, Sa-Nguanmoo P, Mahachai V, Theamboonlers A and Poovorawan Y: A case-control study on sequence variations in the enhancer II/core promoter/precore and X genes of hepatitis B virus in patients with hepatocellular carcinoma. Hepatol Int 4: 577-584, 2010.

22. Li W, Chen G, Yu X, Shi Y, Peng M and Wei J: Accumulation of the mutations in basal core promoter of hepatitis $\mathrm{B}$ virus subgenotype $\mathrm{C} 1$ increase the risk of hepatocellular carcinoma in Southern China. Int J Clin Exp Pathol 6: 1076-1085, 2013.

23. Lyu H, Lee D, Chung YH, Kim JA, Lee JH, Jin YJ, Park W, Mathews P, Jaffee E, Zheng L, et al: Synergistic effects of A1896, T1653 and T1762/A1764 mutations in genotype c2 hepatitis B virus on development of hepatocellular carcinoma. J Viral Hepat 20: 219-224, 2013. 
24. Huang $X$ and Hollinger FB: Occult hepatitis B virus infection and hepatocellular carcinoma: A systematic review. J Viral Hepat 21: 153-162, 2014.

25. Lin CL, Chen JD, Liu CJ, Lee PH, Chen PJ, Lai MY, Kao JH and Chen DS: Clinicopathological differences between hepatitis B viral genotype B- and C-related resectable hepatocellular carcinoma. J Viral Hepat 14: 64-69, 2007.

26. Kay A and Zoulim F: Hepatitis B virus genetic variability and evolution. Virus Res 127: 164-176, 2007.

27. Yim HJ and Lok AS: Natural history of chronic hepatitis B virus infection: What we knew in 1981 and what we know in 2005 . Hepatology 43 (Suppl 1): S173-S181, 2006.

28. Jammeh S, Tavner F, Watson R, Thomas HC and Karayiannis P: Effect of basal core promoter and pre-core mutations on hepatitis B virus replication. J Gen Virol 89: 901-909, 2008.
29. Buckwold VE, Xu Z, Chen M, Yen TS and Ou JH: Effects of a naturally occurring mutation in the hepatitis $\mathrm{B}$ virus basal core promoter on precore gene expression and viral replication. J Virol 70: 5845-5851, 1996.

30. Yin J, Zhang H, Li C, Gao C, He Y, Zhai Y, Zhang P, Xu L, Tan X, Chen J, et al: Role of hepatitis B virus genotype mixture, subgenotypes $\mathrm{C} 2$ and $\mathrm{B} 2$ on hepatocellular carcinoma: Compared with chronic hepatitis B and asymptomatic carrier state in the same area. Carcinogenesis 29: 1685-1691, 2008.

31. Yang HI, Yeh SH, Chen PJ, Iloeje UH, Jen CL, Su J, Wang LY, Lu SN, You SL, Chen DS, et al; REVEAL-HBV Study Group: Associations between hepatitis B virus genotype and mutants and the risk of hepatocellular carcinoma. J Natl Cancer Inst 100: 1134-1143, 2008. 